\title{
The Effects of Sprint Interval vs. Continuous Endurance Training on Physiological And Metabolic Adaptations in Young Healthy Adults
}

\author{
by \\ Gulbin Rudarli Nalcakan ${ }^{1}$
}

\begin{abstract}
The purpose of this study was to compare the effects of sprint interval training (SIT) and continuous endurance training (CET) on selected anthropometric, aerobic, and anaerobic performance indices as well as the blood lipid profile, inflammatory and muscle damage markers in healthy young males. Fifteen recreationally active male volunteers (age: $21.7 \pm 2.2$ years, body mass: $83.0 \pm 8.0 \mathrm{~kg}$, body height: $1.82 \pm 0.05 \mathrm{~m}$ ) were divided into two groups according to their initial $\mathrm{VO}_{2}$ max levels. Training programs were conducted 3 times per week for 7 weeks. The SIT program consisted of 4-6 Wingate anaerobic sprints with a 4.5 min recovery, while CET consisted of 30-50 min cycling at $60 \% \mathrm{VO}_{2}$ max. Biochemical, anthropometric and fitness assessments were performed both pre and post-intervention. Significant improvements in $\mathrm{VO}_{2} m a x$, anaerobic power and capacity, and $\mathrm{VO}_{2}$ utilization during the submaximal workout and significant decreases in body fat and in waist circumference after the intervention occurred in both SIT and CET groups. Significantly greater gross efficiency was measured in the CET group. No differences in the lipid profile or serum levels of inflammatory, myocardial and skeletal muscle damage markers were observed after the training period. The study results agree with the effectiveness of a $30 \mathrm{~s}$ all-out training program with a reduced time commitment for anthropometric, aerobic and anaerobic adaptation and eliminate doubts about its safety as a model.
\end{abstract}

Key words: gross efficiency, inflammation, lipids, muscle damage, $V_{2} m a x$, Wingate test.

\section{Introduction}

Epidemiological studies have shown that low aerobic capacity is associated with higher rates of cardiovascular diseases, type 2 diabetes mellitus, cancer and mortality (Gist et al., 2014). To lower the disease risk, continuous endurance training (CET) such as running, brisk walking or cycling at moderate intensity is the recommended exercise modality, including 150-250 min $\bullet$ wk-1 activity (Donnelly et al., 2009). As lack of time is a commonly cited reason for physical inactivity, thus, the apparent time efficiency of sprint interval training (SIT) has significant implications for this form of exercise (Burgomaster et al., 2008; Gibala et al., 2006).

It was recently reported that the SIT modality was effective in decreasing subcutaneous fat tissue (Boer et al., 2013), especially in abdominal fat (Boutcher, 2011) and total body weight (Perry et al., 2008), and improving blood lipid and lipoprotein profiles (O'Donovan et al., 2005), aerobic performance and skeletal muscle oxidative capacity (Gibala et al., 2006; Burgomaster et al., 2005), post-exercise fat oxidation and energy consumption (Stepto et al., 2001; King et al., 2002), as well as peak power and mean power output (Bayati et al., 2011; Siahkouhian et al., 2013).

The main ATP resynthesis pathway during CET would be expected to rely on predominantly aerobic energy turnover, whereas

1 - Ege University School of Physical Education and Sports, Bornova - Izmir - Turkiye. 
SIT relies on anaerobic metabolism. Approximately 15 to $20 \%$ of total energy is supplied from oxidative metabolism during a single 30-s Wingate all-out cycling bout (Ozkaya et al., 2014). However, ATP provision derived from oxidative metabolism increases if the exercise bouts are extended (Parolin et al., 1999). The increased contribution from oxidative metabolism during repeated high-intensity effort is attributable to both an increased rate of oxygen transport and utilization and a decreased ability to stimulate ATP production through the breakdown of phosphocreatine and glycogen (Parolin et al., 1999). Nevertheless, it appears that SIT induces the same physiological and metabolic adaptations as traditional CET. These muscle adaptations have been associated with improved glycemic control and insulin sensitivity (Sloth et al., 2013). In contrast, the improvements observed in muscular oxidative capacity are related to work loads and fluctuations in oxygen uptake during exercise rather than to exercise duration and energy consumption (Daussin et al., 2008).

Although health- and fitness-related benefits of SIT have been demonstrated, it is premature to recommend the SIT modality, particularly to a population with cardiovascular disease as well as older and sedentary individuals (Whyte et al., 2010). Although SIT might be considered an appropriate physical activity option for healthy young people, intense training induces impaired immune responses (Robson-Ansley et al., 2007), increased skeletal muscle damage (Clarkson and Hubal, 2002) and myocardial cell injury (Rogers et al., 1985; Vidotto et al., 2005). However, it is unknown whether this form of exercise can be tolerated by healthy young people whose fitness level is low.

Although currently available literature has focused on the basic fitness effects of the allout sprint interval modality, there is a lack of experimental studies that evaluate SIT effects vs. CET based on fitness, general health and safety aspects considered together. Therefore, the aim of this study was to compare the effects of SIT and CET on anthropometric, aerobic, anaerobic performance indices, mechanical gross efficiency, blood lipids, inflammation, skeletal muscle damage and myocardial cell injury in healthy young males. It was hypothesized that similar anthropometric, physiological and biochemical progress and adaptation would be observed in SIT and CET.

\section{Material and Methods}

\section{Participants}

Fifteen healthy young recreationally active university students (mean \pm standard deviation; age: $21.7 \pm 2.2$ years, body mass index (BMI): 25.0 $\pm 2.1 \mathrm{~kg} \cdot \mathrm{m}^{-2}$, percentage of body fat (BF\%): 16.2 $\pm 3.2 \%, \quad V_{2}$ max: $\left.\quad 40.3 \quad \pm 5.0 \quad \mathrm{ml} \cdot \mathrm{min}^{-1} \cdot \mathrm{kg}^{-1}\right)$ volunteered to participate in this investigation. All participants were habitually active but not engaged in any sort of structured training program, nor had they been so engaged for at least 5 months prior to the study. They were instructed not to perform additional exercise, modify their regular daily diet regimen, or take any medications or supplements during the study period. After routine medical screening, the subjects were informed of the procedures to be employed in the study and associated risks, and all provided written informed consent. The experimental protocol was approved by the Local Scientific Research Ethics Board (approval no: 20.478.486-278).

\section{Experimental Design}

A repeated measures study design was used for this prospective laboratory experiment. Prior to any baseline testing, all participants visited the laboratory for fasting blood samples and body composition measurements. The following day, they participated in a familiarization session to minimize any learning effect and to adapt to the testing/training procedures, the laboratory environment and our study group. Before the training periods, a submaximal test, a maximal graded exercise test and then a verification phase were performed to determine the initial $\mathrm{VO}_{2} \max$ levels of the volunteers. A 30-second Wingate all-out test was conducted to measure anaerobic indices. A 30-min constant-loading submaximal test was then performed. All these tests were separated by intervals of at least 24 hours. Subjects were matched according to their initial $\mathrm{VO}_{2}$ max levels and divided into two groups as follows (numbers indicate ranking of $\mathrm{VO}_{2}$ max values; $1=$ the highest, $15=$ the lowest $)$ :

\begin{tabular}{lllllllll}
\hline CET: & 1 & 4 & 5 & 8 & 9 & 12 & 13 & \\
SIT: & 2 & 3 & 6 & 7 & 10 & 11 & 14 & 15 \\
\hline
\end{tabular}


After the baseline measurements were completed, the subjects began their 7-week sprint interval or continuous endurance training. In the middle of the training period, a graded exercise test was performed to reregulate the training loads. At the end of the training period, the baseline tests were repeated in the same order. Standard environmental conditions $\left(20-23{ }^{\circ} \mathrm{C}\right.$ ambient temperature, $55-65 \%$ relative humidity) were ensured during the testing sessions.

\section{Anthropometric Measurements}

The anthropometric measurements were performed by the same researcher on all subjects according to the Anthropometric Standardization Reference Manual (Lohman et al., 1988). The BMI was calculated from height and body mass with the formula body mass $(\mathrm{kg}) /$ height $\left(\mathrm{m}^{2}\right)$. All subcutaneous skinfold measurements were taken with a Holtain skinfold caliper (Holtain Ltd., UK) in triplicate. $\mathrm{BF} \%$ was calculated using the Faulkner equation (Martínez et al., 2011). The sum of eight skinfolds (SS) (thicknesses of the triceps, biceps, chest, subscapula, suprailiac, abdominal, thigh and calf) was also evaluated. Waist circumference was measured midway between the lower rib margin and iliac crest. Hip circumference was measured at the level of widest circumference over the greater trochanters. The waist-to-hip ratio $(\mathrm{W} / \mathrm{H})$ was calculated as waist circumference divided by hip circumference.

\section{Physiological Measurements}

Oxygen uptake was measured breath-bybreath using a Cosmed Quark b2 (Cosmed Srl, Rome, Italy) with expired gas concentrations. The Quark b2 was calibrated according to the manufacturer's instructions. The turbine flow meter was calibrated using a 3-L syringe (Quinton Instruments, USA). HR data were collected with a system compatible with the same gas analyzer (Polar Electro OY, Kempele, Finland).

\section{Familiarization Sessions}

The participants visited the laboratory before the main study. The aim of this visit was to adapt the participants to the laboratory environment and staff and, in addition, to minimize the learning effect and to familiarize the participants with the testing/training procedures. The familiarization sessions for the submaximal and maximal graded exercise tests consisted of four 5-min stages. The first stage was initiated with a workload of 60-80 Watts and continued in $\sim 10$ Watt increases. To become familiar with the Wingate all-out test procedures, the participants performed a Wingate test trial. All procedures were performed on a mechanically braked cycle ergometer (894E, Monark, Sweden) which was set up to replicate the participant's normal riding position for all tests.

\section{Submaximal Tests}

The purpose of this test was to determine the initial load for the maximal graded exercise test. Therefore, the submaximal test consisted of four 5-min stages in which load increments were included to keep the subjects within the limits of the predicted aerobic threshold (heartbeat of 130$150 \mathrm{bpm}$ ) and anaerobic threshold (heartbeat of 150-170 bpm). Respiratory exchange dynamics were also considered in accordance with the $\mathrm{VE} / \mathrm{VO}_{2}$. The cadence was fixed at $60 \mathrm{rpm}$ for the test.

\section{Maximal Graded Exercise Tests and Verification Phases}

The initial loads of the graded $\mathrm{VO}_{2}$ max test were adjusted to the respiratory anaerobic threshold level predicted from the submaximal test. The test focused on voluntary exhaustion by $10 \pm 2 \mathrm{~min}$ and was fixed at $60 \mathrm{rpm}$. Accordingly, the test load was increased by $\sim 20$ Watts at the 4th, 6th, 8th, 10th, 11th and 12th min. $\mathrm{VO}_{2}$ max was calculated as the highest value of oxygen uptake observed over a 30 -s period. $\mathrm{VO}_{2}$ max was confirmed when three or more of the following criteria were met: (1) a plateau in $\mathrm{VO}_{2}$ despite an increase in the work load, (2) a respiratory exchange ratio (RER) higher than 1.2, (3) a peak heart rate at least equal to $90 \%$ of the agepredicted maximum, and/or (4) visible exhaustion. The subjects were given strong verbal encouragement to exercise until volitional exhaustion but were not given progress feedback. The purpose of the verification test was to confirm the $\mathrm{VO}_{2} \mathrm{max}$ level. This test started with the laststage load of the incremental test and continued until voluntary exhaustion occurred between the 4th and 7th min of the test.

\section{Constant-Loading Submaximal Tests}

The 30-min exercises were completed at the load corresponding to $60 \%$ of the $\mathrm{VO}_{2}$ max. The mechanical gross efficiency (GE\%) was calculated to show the metabolic efficiency in the constant- 
loading submaximal tests. Metabolic rate (MR) was calculated with the formula given by Nishi (1981), MR $(\mathrm{W})=21 \times(0.23 \times \mathrm{RER}+0.77) \times\left(\mathrm{VO}_{2}\right)^{-1}$, where GE is defined as the measured mechanical power output divided by the calculated MR.

\section{Wingate All-Out Test}

The participants performed a standardized 5-min warm up prior to experimental data collection and performed the test against a resistance equivalent to $7.5 \%$ of the subject's body mass. They were instructed to pedal as rapidly as possible against the ergometer's inertial resistance. The appropriate load was then applied to allow the participants to start at $120 \mathrm{rpm}$, and data capture was initiated. The subjects were verbally encouraged to pedal continuously throughout the 30-s test. Peak power (PP), average power (AP), power drop (PD), the fatigue index (FI) and time to reach PP (tPP) were then calculated over the Wingate test. The FI (\%) was determined over the mean power data for the 5-s intervals, whereas the PD (\%) was calculated based on the instantaneous power data obtained with millisecond sensitivity.

\section{Biochemical Measurements}

Fasting blood samples were collected in the morning (08.00-10.00 a.m.) by the same investigator and collected from an antecubital forearm vein, then centrifuged at $4000 \mathrm{rpm}$ for 10 min, extracted and placed into plastic storage vacutainers to attempt to control for the lipid profile, inflammation, myocardial and skeletal muscle damage. White blood cell (WBC) levels were analyzed in an automated COULTER ${ }^{\circledR}$ LH 780 Hematology Analyzer, whereas analyses of cardiac troponin I (cTnI) levels were performed by an automated chemiluminescence system (Beckman Coulter Access 2). Creatine kinase (CK), creatine kinase-myocardial band (CK-MB), aspartate aminotransferase (AST), alanine aminotransferase (ALT), C-reactive protein (CRP), total cholesterol (TC), very low-density lipoprotein (VLDL), high-density lipoprotein (HDL), and triglyceride (TG) levels were quantified in an automated Beckman Coulter Olympus $\mathrm{Au} 2700$ chemical analyzer. Lowdensity lipoprotein (LDL) content was calculated from the Friedewald formula.

\section{Training Intervention}

The SIT program consisted of 4-6 Wingate anaerobic sprints with a 4.5-min recovery, and the CET program consisted of 30-50 min of cycling at $60 \%$ of $\mathrm{VO}_{2}$ max. The loads, repetitions for SIT and time for CET were gradually increased during the training periods. Training was performed three times per week for seven consecutive weeks. A rest of 1-2 days between sessions was provided to promote recovery.

\section{Statistical analysis}

Descriptive statistics were reported as the mean \pm SD. The Shapiro-Wilk $W$ test and Levene's test, respectively, showed that the data obtained met the assumptions of normality and homogeneity of variance. Therefore, parametric statistical tests were used. Group (CET and SIT) was the between-subjects factor, and Time ( 0 . Week and 7. Week) was the within-subjects factor in the present study. The main effects and the interaction effect of these factors on the dependent variables were assessed using a $2 \times 2$ (Group $\times$ Time) two-factor mixed-design analysis of variance (ANOVA). Aerobic power indices were measured at three different time points $(0$, Week 3 , Week 7) across the study. Therefore, a $2 \times 3$ (Group $\times$ Time) two-factor mixed-design ANOVA was used in the analysis of these variables. In case of a significant Time effect or Group $\times$ Time interaction effect, a one-factor repeated measures ANOVA with the Bonferroni post-hoc procedure was performed to identify the source of the difference. These tests were also performed in case of insignificant overall mixed-design ANOVA results to identify the effect size (d) of the difference, which is an important determinant of practical significance. The effect size of the difference was evaluated using the classification of Cohen ( $<0.2$ trivial, $0.2 \leq \mathrm{d}<0.5$ small, $0.5 \leq \mathrm{d}<0.8$ moderate, $\mathrm{d} \geq 0.8$ large effect size). Baseline values of dependent variables were compared between CET and SIT using an independent-samples t-test. The level of statistical significance was set at $p \leq$ 0.05 .

\section{Results}

Because of health problems and the intensive test program, three participants failed to continue the experimental study. As a result, the experimental phase was completed by 15 participants. After the performance of 21 sessions over 7 weeks, waist and hip circumference, $\mathrm{BF} \%$ and SS in the CET, waist circumference, $W / H$, 
$\mathrm{BF} \%$ and SS in the SIT significantly decreased. There were no significant differences between CET and SIT in anthropometric results (Table 1)

Statistically significant main effects for time were detected for BF $(\mathrm{p}<0.001, \eta p 2=0.057)$, SS $(\mathrm{p}<0.001, \quad \eta \mathrm{p} 2=0.643), \quad \mathrm{VO}_{2} \max \quad(\mathrm{p}<0.001$, $\eta \mathrm{p} 2=0.698), \mathrm{PP}(\mathrm{p}<0.001, \eta \mathrm{p} 2=0.669), \operatorname{AP}(\mathrm{p}<0.001$, $\eta p 2=0.729)$, FI $(p=0.027, \eta p 2=0.324)$, tPP $(p<0.016$, $\eta p 2=0.371), G E(p<0.001, \eta p 2=0.645)$, and $c T n I$ $(\mathrm{p}<0.021, \eta \mathrm{p} 2=0.348)$. However, no significant Group $\times$ Time interaction effect was found for any of the dependent variables, indicating that changes in these variables over the course of the study showed similar patterns in the CET and SIT groups.
Among the aerobic fitness variables, there were significant differences for maximal oxygen uptake $\left(\mathrm{VO}_{2} \max \right)$ values at pre, mid and post-test (W0-W3-W7) in the CET group, and there were also significant improvements among the $\mathrm{VO}_{2}$ max values at pre, mid and post-test (W0-W3-W7), except between W0 and W3, in the SIT group. $\mathrm{VO}_{2}$ max improvement was similar in the CET $(8.7 \%)$ and SIT $(7.0 \%)$ groups. There were no significant differences between CET and SIT in the indices of the aerobic power test (Table 2).

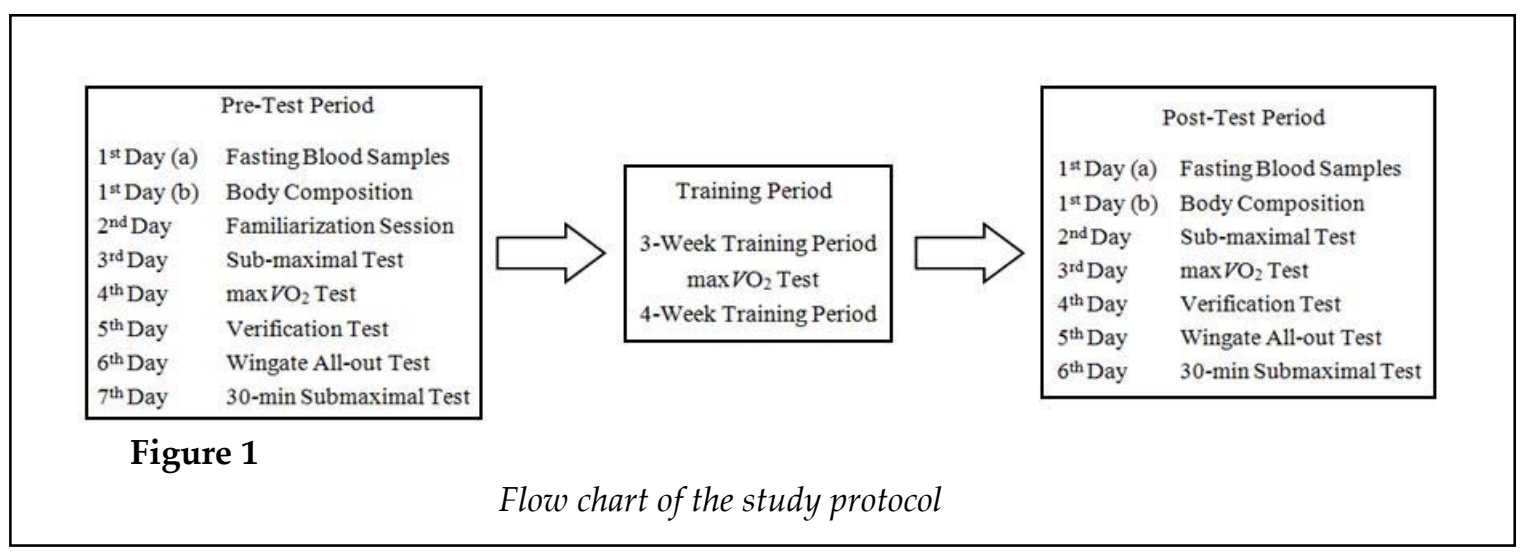

\begin{tabular}{|c|c|c|c|c|c|c|c|c|c|c|c|c|c|c|}
\hline & & & & & & & & \multicolumn{7}{|c|}{ Table 1} \\
\hline & \multicolumn{14}{|c|}{ Influence of CET and SIT on anthropometric indices } \\
\hline & \multicolumn{7}{|c|}{$\operatorname{CET}(\mathrm{n}=7)$} & \multicolumn{7}{|c|}{ SIT $(\mathrm{n}=8)$} \\
\hline \multirow{3}{*}{ 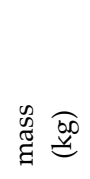 } & $\begin{array}{l}\text { Week } \\
\text { No }\end{array}$ & M & \pm & SD & $\Delta \%$ & $\mathrm{p}$ & $\mathrm{d}$ & $\begin{array}{l}\text { Week } \\
\text { No }\end{array}$ & M & \pm & SD & $\Delta \%$ & $\mathrm{p}$ & $\mathrm{d}$ \\
\hline & W0 & 79.3 & \pm & 6.69 & \multirow{2}{*}{-1.1} & \multirow{2}{*}{0.140} & \multirow{2}{*}{-0.132} & Wo & 86.2 & \pm & 8.00 & \multirow{2}{*}{-0.6} & \multirow{2}{*}{0.530} & \multirow{2}{*}{-0.065} \\
\hline & W7 & 78.4 & \pm & 6.96 & & & & W7 & 85.7 & \pm & 7.42 & & & \\
\hline \multirow{2}{*}{ 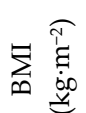 } & W0 & 24.5 & \pm & 1.90 & \multirow[b]{2}{*}{-1.2} & \multirow[b]{2}{*}{0.137} & \multirow[b]{2}{*}{-0.154} & W0 & 25.5 & \pm & 2.23 & \multirow[b]{2}{*}{-0.8} & \multirow[b]{2}{*}{0.573} & \multirow[b]{2}{*}{-0.090} \\
\hline & W7 & 24.2 & \pm & 2.00 & & & & W7 & 25.3 & \pm & 2.20 & & & \\
\hline \multirow{4}{*}{ 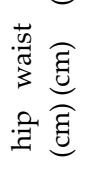 } & Wo & 82.4 & \pm & 3.94 & \multirow{2}{*}{-3.9} & \multirow{2}{*}{$0.001^{*}$} & \multirow{2}{*}{-0.868} & W0 & 86.8 & \pm & 7.88 & \multirow{2}{*}{-3.3} & \multirow{2}{*}{$0.023^{*}$} & \multirow{2}{*}{-0.393} \\
\hline & W7 & 79.2 & \pm & 3.41 & & & & W7 & 83.9 & \pm & 6.85 & & & \\
\hline & W0 & 100 & \pm & 4.86 & \multirow{2}{*}{-4.0} & \multirow{2}{*}{$0.002^{*}$} & \multirow{2}{*}{-0.711} & Wo & 102 & \pm & 4.11 & \multirow{2}{*}{-0.1} & \multirow{2}{*}{0.479} & \multirow{2}{*}{0.239} \\
\hline & W7 & 96.0 & \pm & 6.30 & & & & W7 & 101 & \pm & 4.24 & & & \\
\hline \multirow{2}{*}{$\frac{\pi}{3} \stackrel{\varrho}{\varrho}$} & Wo & 0.82 & \pm & 0.31 & 12 & 0.655 & 0,030 & W0 & 0.85 & \pm & 0.48 & & & \\
\hline & W7 & 0.83 & \pm & 0.36 & 1,2 & 0.655 & 0.030 & W7 & 0.83 & \pm & 0.51 & -2.4 & $0.033^{*}$ & -0.040 \\
\hline 政 & W0 & 15.8 & \pm & 2.62 & -57 & $0015 *$ & -0343 & W0 & 16.5 & \pm & 3.72 & -73 & $0007 *$ & -0348 \\
\hline & W7 & 14.9 & \pm & 2.63 & -5.7 & $0.015^{n}$ & -0.343 & W7 & 15.3 & \pm & 3.15 & -7.3 & $0.007^{n}$ & -0.348 \\
\hline$\infty \widehat{g}$ & Wo & 114 & \pm & 24.3 & & & & Wo & 124 & \pm & 43.1 & & & \\
\hline है & W7 & 102 & & 26.7 & -10.5 & $0.015^{*}$ & -0.470 & W7 & & \pm & & -10.5 & $0.010^{*}$ & -0.327 \\
\hline & & $\begin{array}{r}{ }^{*} \\
B M I:\end{array}$ & $M$ & $\begin{array}{l}\text { mean } \\
0.2 \mathrm{tr}\end{array}$ & $\begin{array}{l}\text { : conti } \\
\text { index, } \\
\text { SD: } s \\
\text { ivial; } 0\end{array}$ & $\begin{array}{l}\text { uous en } \\
\text { I/H: wa } \\
\leq d<0 \text {. }\end{array}$ & $\begin{array}{l}\text { durance } \\
\text { ist-to-hip } \\
\text { leviation, } \\
5 \text { small; } \\
\text { W: }\end{array}$ & $\begin{array}{l}\text { aining, } \\
\text { atio, BF } \\
\% \text { : per } \\
\leq d<0 \\
\text { ek }\end{array}$ & $\begin{array}{l}\text { SIT: sf } \\
\text { body } \\
8 \text { montag } \\
8 \text { moo }\end{array}$ & & $\begin{array}{l}\text { inter } \\
\text { SS: sh } \\
\text { inge i } \\
e ; d \geq\end{array}$ & $\begin{array}{l}2 \text { train } \\
\text { of } 8 \mathrm{sl} \\
\text { means, } \\
8 \text { large }\end{array}$ & $\begin{array}{l}\text { ing, } \\
\text { kinfolds } \\
\text { effects }\end{array}$ & \\
\hline
\end{tabular}




\begin{tabular}{|c|c|c|c|c|c|c|c|c|c|c|c|c|}
\hline \multirow{6}{*}{ 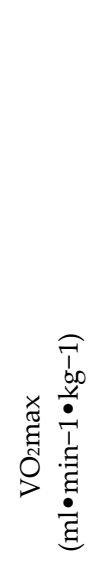 } & \multicolumn{12}{|c|}{ Influence of CET and SIT on indices of the aerobic power test } \\
\hline & \multicolumn{6}{|c|}{$\operatorname{CET}(\mathrm{n}=7)$} & \multicolumn{6}{|c|}{$\operatorname{SIT}(n=8)$} \\
\hline & $\begin{array}{c}\text { Week } \\
\text { No }\end{array}$ & $\mathrm{M} \pm \mathrm{SD}$ & $\begin{array}{l}\text { Paired } \\
\text { Weeks }\end{array}$ & $\Delta \%$ & $\mathrm{p}$ & $\mathrm{d}$ & $\begin{array}{c}\text { Week } \\
\text { No }\end{array}$ & $\mathrm{M} \pm \mathrm{SD}$ & $\begin{array}{l}\text { Paired } \\
\text { Weeks }\end{array}$ & $\Delta \%$ & $\mathrm{p}$ & d \\
\hline & W0 & $40.5 \pm 6.0$ & W3-W0 & 4.4 & $0.038^{*}$ & 0.327 & W0 & $40.2 \pm 4.3$ & W3-W0 & 3.0 & 0.099 & 0.292 \\
\hline & W3 & $42.3 \pm 5.0$ & W7-W3 & 4.1 & $0.018^{*}$ & 0.358 & W3 & $41.4 \pm 3.9$ & W7-W3 & 3.9 & $0.009^{*}$ & 0.410 \\
\hline & W7 & $44.0 \pm 4.8$ & W7-W0 & 8.7 & $0.014^{*}$ & 0.654 & W7 & $43.0 \pm 3.9$ & W7-W0 & 7.0 & $0.022^{*}$ & 0.682 \\
\hline \multicolumn{13}{|c|}{$\begin{array}{c}* p \leq 0.05, C E T: \text { continuous endurance training, SIT: sprint interval training, VO2max: } \\
\text { maximal oxygen consumption, M: mean, SD: standard deviation, } \Delta \% \text { : percentage change } \\
\text { in means, } d: \text { Cohen's } d(<0.2 \text { trivial; } 0.2 \leq d<0.5 \text { small; } 0.5 \leq d<0.8 \text { moderate; } d \geq 0.8 \\
\text { large effect size), W: week }\end{array}$} \\
\hline
\end{tabular}

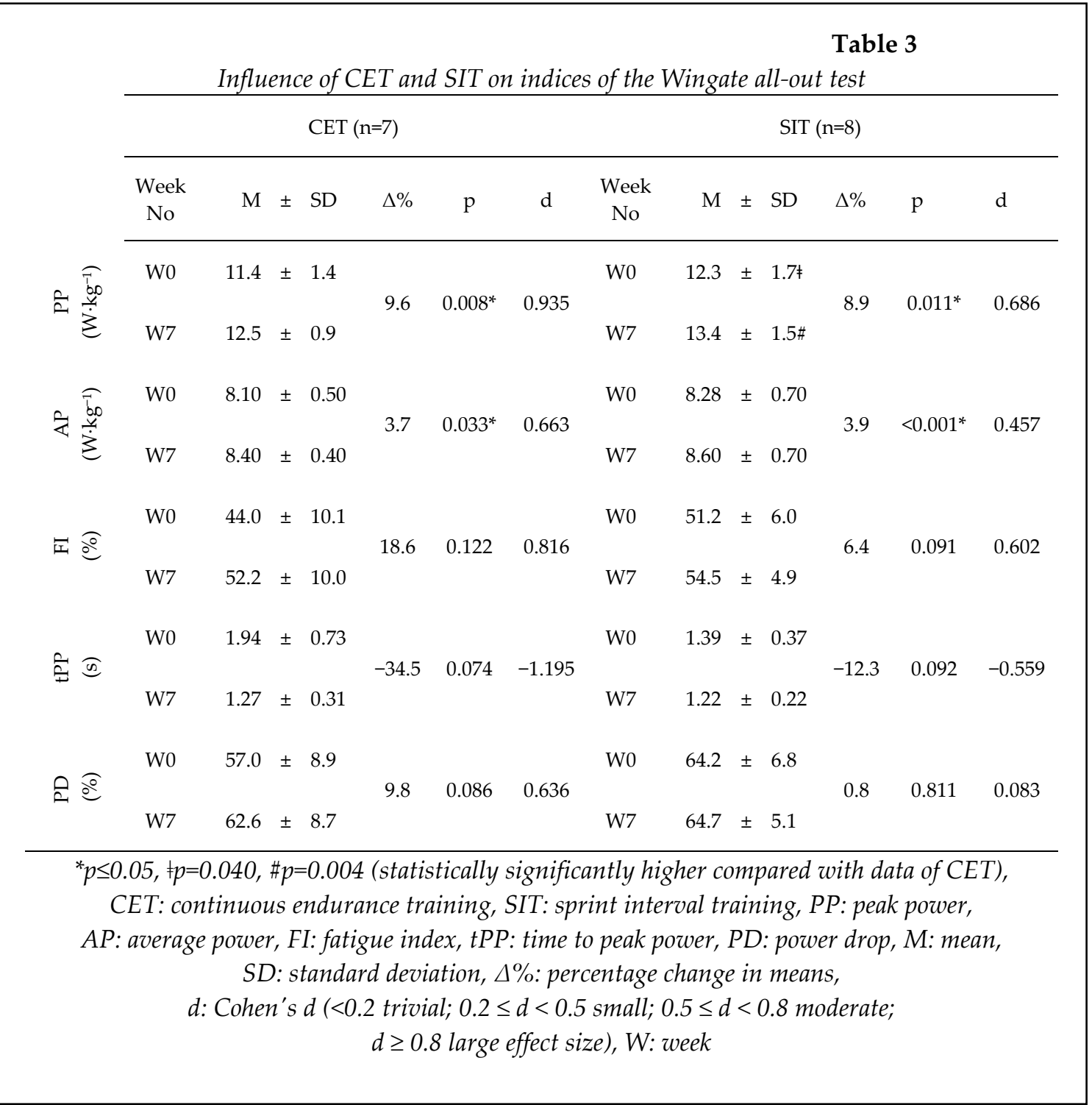




\begin{tabular}{|c|c|c|c|c|c|c|c|c|c|c|c|c|c|}
\hline \multirow{5}{*}{$\rho^{2}$} & \multicolumn{13}{|c|}{$\begin{array}{l}\text { Table } 4 \\
\text { Influence of CET and SIT on indices of gross efficiency }\end{array}$} \\
\hline & \multicolumn{6}{|c|}{ CET $(\mathrm{n}=7)$} & \multicolumn{7}{|c|}{ SIT $(\mathrm{n}=8)$} \\
\hline & $\begin{array}{l}\text { Week } \\
\text { No }\end{array}$ & $\mathrm{M}$ & $\pm \mathrm{SD}$ & $\Delta \%$ & $\mathrm{p}$ & $\mathrm{d}$ & $\begin{array}{l}\text { Week } \\
\text { No }\end{array}$ & $\mathrm{M}$ & \pm & SD & $\Delta \%$ & $\mathrm{p}$ & d \\
\hline & & 1.96 & \pm 0.34 & \multirow{2}{*}{12.8} & \multirow{2}{*}{$0.011^{*}$} & \multirow{2}{*}{0.826} & & & \pm & & \multirow[t]{2}{*}{18.3} & \multirow[t]{2}{*}{$0.001^{*}$} & \multirow[t]{2}{*}{1.765} \\
\hline & W7 & 2.21 & \pm 0.26 & & & & W7 & 2.33 & \pm & 0.16 & & & \\
\hline \multirow{2}{*}{ 붱 } & W0 & 16.3 & \pm 1.59 & \multirow[t]{2}{*}{18.4} & \multirow[t]{2}{*}{$0.001^{*}$} & \multirow[t]{2}{*}{1.558} & W0 & 17.3 & \pm & 2.43 & \multirow[t]{2}{*}{8.8} & \multirow[t]{2}{*}{0.071} & \multirow[t]{2}{*}{0.800} \\
\hline & W7 & 19.3 & $\pm \quad 2.21$ & & & & W7 & 18.8 & \pm & 1.19 & & & \\
\hline \multicolumn{14}{|c|}{$\begin{array}{c}\text { * } p \leq 0.05, C E T \text { : continuous endurance training, SIT: sprint interval training, } \\
\text { GE: gross efficiency, VO2: oxygen consumption, } M: \text { mean, } S D \text { : standard deviation, } \\
\Delta \% \text { : percentage change in means, } d \text { : Cohen's } d(<0.2 \text { trivial; } 0.2 \leq d<0.5 \text { small; } \\
0.5 \leq d \leq 0.8 \text { moderate; } d>0.8 \text { large effect size), W: week }\end{array}$} \\
\hline
\end{tabular}

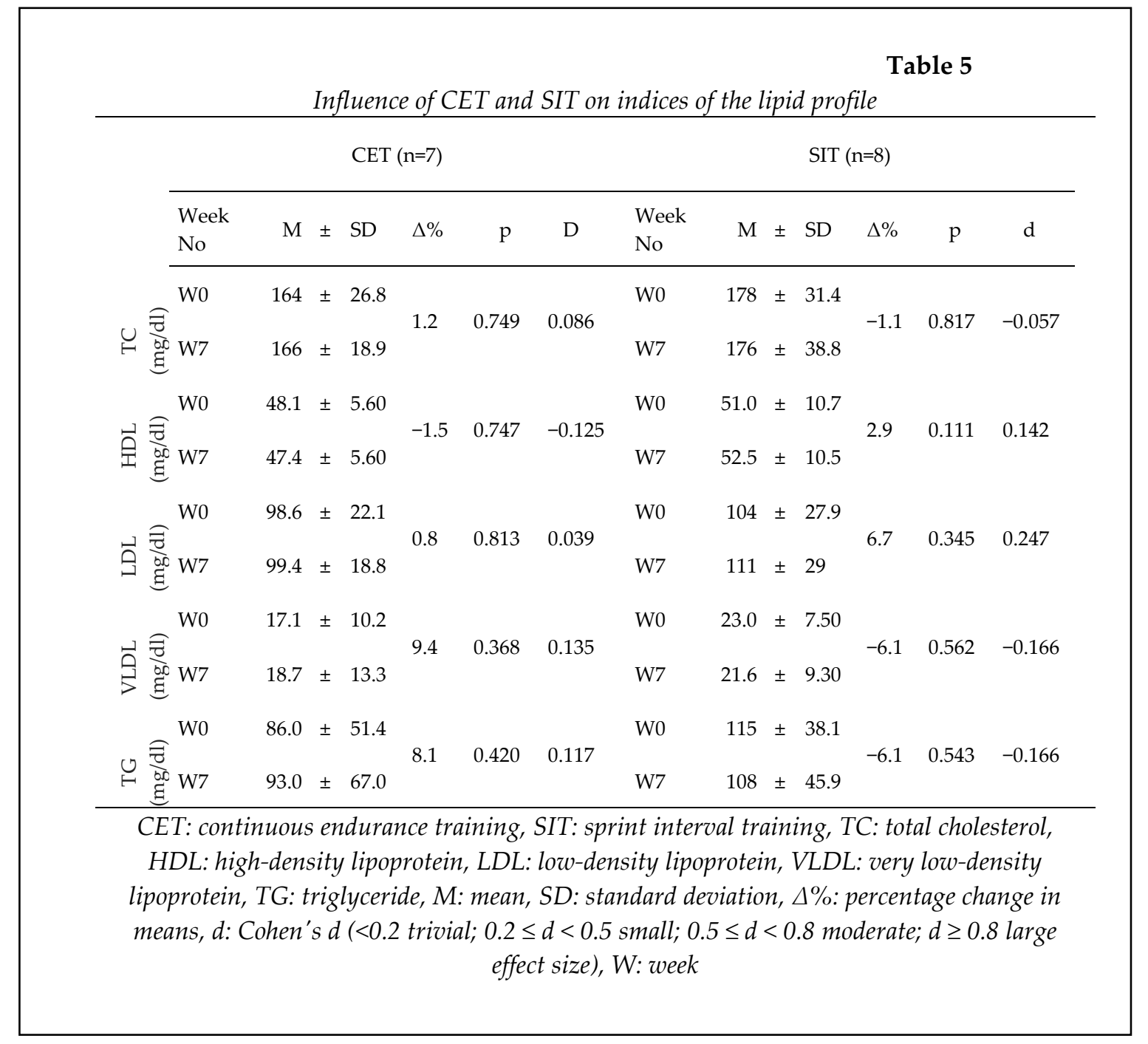




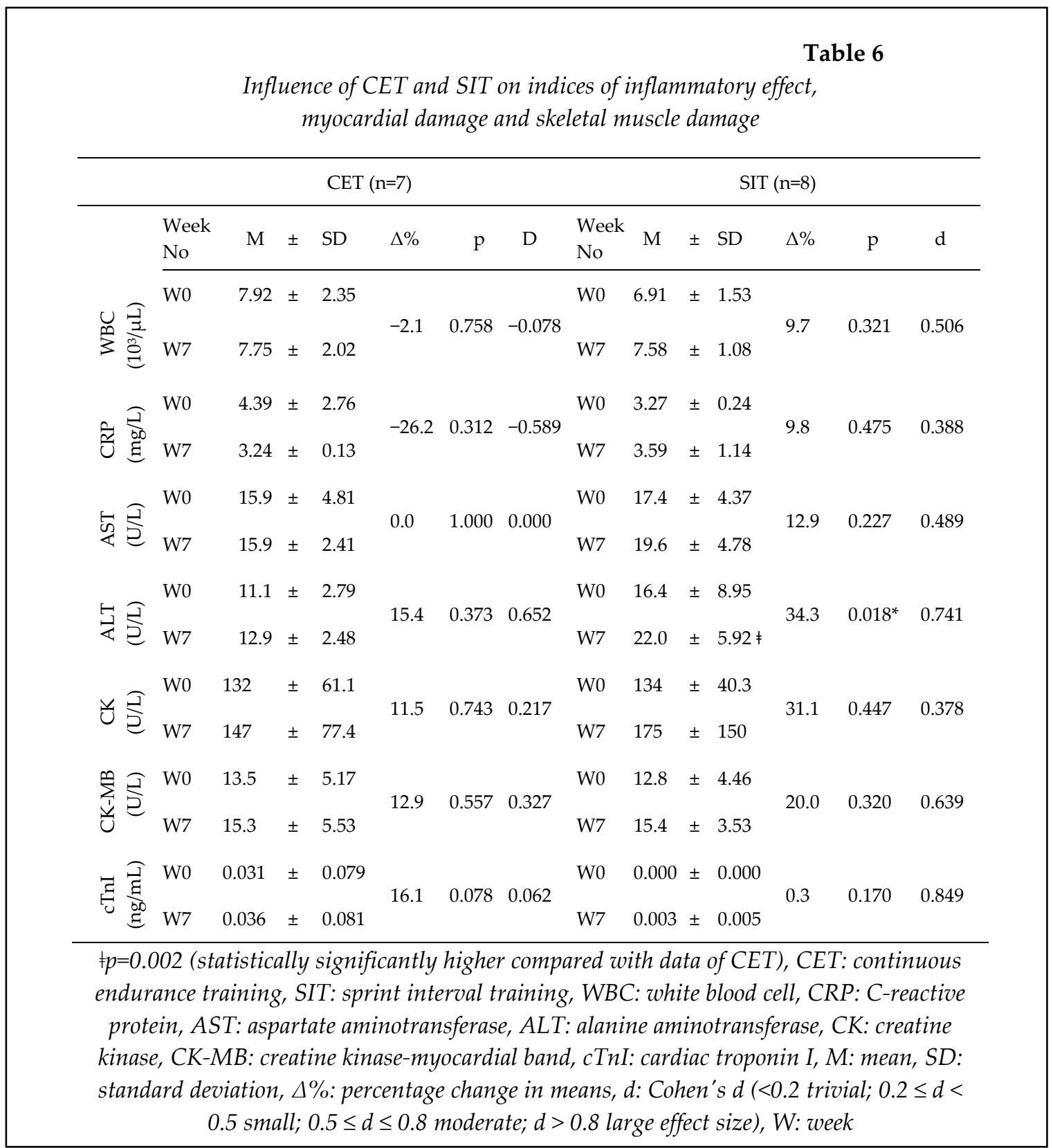

Table 3 shows that there were significant differences between the pre and post-test PP $(\mathrm{W} / \mathrm{kg})$ results between groups $(0.008$ and 0.011 , respectively). After the 7-week training periods, only PP (W·kg-1) and AP (W·kg-1) increased significantly in the CET and SIT groups.

To calculate the GE (\%), the participants performed a 30 -min submaximal test $(60 \%$ of $\mathrm{VO}_{2} \mathrm{max}$ ) with constant loading. According to the test results, oxygen uptake per liter $\left(\mathrm{VO}_{2}\right)$ was significantly increased in the CET and SIT groups, whereas GE\% was significantly improved only in the CET group. No differences in these parameters were found between groups (Table 4).

Our results showed that the type and duration of training had no significant effect on the cholesterol profile (LDL, HDL, VLDL, TC, TG), serum levels of inflammatory markers (CRP, WBC), myocardial cell injury markers (cTnI and CK-MB) or skeletal muscle damage markers (CK, ALT, and AST) ( $>0.05)$. The levels of the CRP and WBC counts differed between the two training groups. Although they increased $(9.7 \%$, $9.8 \%)$ after SIT and decreased $(2 \%, 26 \%)$ for WBC 
and CRP after CET, these differences were not statistically significant (Tables 5 and 6).

\section{Discussion}

Although many exercise programs prescribed for fat reduction involve continuous and moderate aerobic exercise, the SIT modality may be as successful as traditional methods for fat loss. Indeed, it has been shown that SIT may be preferable for reducing body fat (Hazell et al., 2014; Macpherson et al., 2011) and decreasing waist and hip circumference (Whyte et al., 2010). The results of the present study demonstrated significant decreases in waist circumference, the waist-to-hip ratio and body fat in SIT, with similar results found for the CET group. These results support the hypothesis that increased postexercise $\mathrm{VO}_{2}$, fat oxidation, reduced RER and carbohydrate oxidation after a single SIT bout (Whyte et al., 2010; Hazell et al., 2012) may be significantly related to fat loss. Moreover, the energy cost and $\mathrm{VO}_{2}$ during exercise are relatively low (Hazell et al., 2012; Tremblay et al., 1994). It is known that a decreased waist circumference, as reflected by a reduced abdominal fat mass and the waist-to-hip ratio, is particularly important because of the inverse relationship between abdominal fat and health status.

Although SIT has been used to improve anaerobic performance (Whyte et al., 2010; MacDougall et al., 1998), this exercise modality has recently gained popularity as a means of enhancing aerobic status in only a few sessions (Burgomaster et al., 2005; Burgomaster et al., 2006). The results of the present study showed similar benefits from SIT and from traditional CET (Burgomaster et al., 2008; Gibala et al., 2006; Sandvei et al., 2012). The effectiveness of SIT may stem from a combination of anaerobic and aerobic energy demands. Although the anaerobic contribution is dominant for the first $30 \mathrm{~s}$ all-out bout, the aerobic contribution gradually increases throughout repeated Wingate bouts (Parolin et al., 1999). Gist et al. (2014) have shown that adaptations include rapid increases in muscle oxidative capacity, as reflected by key mitochondrial enzymes, glucose transporters and muscle membrane lactate transporters.

Moreover, aside from changes in anthropometric, aerobic and anaerobic performance indices, the SIT modality may be preferred because of its greater time efficiency compared with CET. Indeed, SIT is a timeefficient strategy for both performance-based programs and commercially available fitness planning purposes. A total of 8.45 hours (only 52.30 min actively) was spent in the SIT modality, whereas a total of 14 hours was spent in CET during the seven-week training period in the present study.

There is no evidence that sprint training produces an increase in GE during submaximal exercise. However, GE is accepted as a key for peak performance for racing distances of 5000 meters and more. It is known that efficiency is a measure of effective work and is most commonly expressed as the percentage of total energy expended that produces external work. The GE of the human body is generally in the range of 10$25 \%$ during submaximal cycle exercise (Moseley and Jeukendrup, 2001). Although GE improvement was significant in CET, it was not significant in the SIT group (18\% vs. $9 \%$ ). These results may imply that the CET modality induces peripheral adaptations in preference to central adjustments. Conversely, SIT appears to induce central adaptations, as evidenced by stroke volume improvement (Trilk et al., 2011).

After exhaustive endurance exercise, muscle damage can be produced by metabolic disturbances associated with ischemia. An increased CK level in the blood after intense exercise may be interpreted as indicating possible mechanical injury to the musculoskeletal system due to the production of an inflammatory response (Toft et al., 2002), but regular training is known to reduce muscle damage caused by exercise (Jaffe et al., 1984), and repeated high doses of exercise at sufficient intervals are known to cause relatively less muscle damage. Priest et al. (1982) confirmed a positive correlation between training status and resting CK and CK-MB levels. The serum AST, ALT, CK and CK-MB activity levels in the SIT group were higher than those in the CET group, indicating intensive exercisecaused muscle cell damage at higher rates in the present study. The increased CK-MB level in skeletal muscle was perhaps due to increases in satellite cells, which repair injured skeletal muscle (Jaffe et al., 1984). Because CK-MB did not increase above $4.5 \%$ as a percentage of total CK, the increase in this isoenzyme originated from skeletal muscle rather than cardiac muscle. 
Moreover, cTnI did not show a statistically significant increase following SIT.

Several studies have been performed to investigate the effects of exercise on cardiac troponins (cTn), which are among the newer cardiac markers; in particular, cTnI can be found in slow and fast-twitch muscles as well as in the myocardium (Davies et al., 1997). It can be accepted that mild increases in serum cTn often follow prolonged endurance exercise (Vidotto et al., 2005), despite contradictions in the literature. These conflicts may result from differences in the fitness levels of participants, the type or duration of exercise, timing of the post-exercise sample, the troponin assay used, and the detection limit used to define a "positive" cTn. Although previous findings strongly suggest that exercise intensity and duration are important determinants of circulating post-exercise $\mathrm{cTn}$, further laboratorybased assessments are needed to clarify this issue (Shave et al., 2010).

It is known that leukocyte count and inflammation markers increase following intense interval training (Robson-Ansley et al., 2007; Markovitch et al., 2008), as increases in inflammatory mediators may indicate their role in muscle tissue repair after anaerobic exercise. However, they have been found to be markedly reduced in skeletal muscle after regular endurance training (Hovanloo et al., 2013). These results are in line with our findings that serum levels of CRP decreased in CET $(26 \%)$ and that WBC and CRP increased in SIT $(9.7 \%$ and $9.8 \%$, respectively), but these differences were not statistically significant.

Studies focused on blood lipid changes in exercise programs of different intensities have obtained controversial results. It has been suggested that high intensities are not required if changes in lipids are the goal of training (Crouse et al., 1997); however, it has been reported that changes in lipids are influenced by exercise intensity (O'Donovan et al., 2005). It has been found that SIT is more effective than CET for improving cholesterol profiles in healthy subjects (Sandvei et al., 2012). Although several studies have focused on the aerobic effects of SIT, knowledge is lacking about the effects of the SIT modality on blood lipid levels. The findings of the current study are consistent with the study of Crouse et al. (1997), which showed no significant effect of exercise intensity on the lipid profile over a course of 24-week cycle ergometer training (Crouse et al., 1997). It should be considered that conclusions drawn from several of the published studies are limited by the absence of a control group, differences among studies in mode and volume of training, subject pre-training lipid levels, diet control, and genetic basis for the elevated cholesterol, as well as by a failure to control for the acute effects of the most recent training session (Crouse et al., 1997).

This study demonstrated that seven weeks of SIT improved body composition, aerobic and anaerobic capacity to an extent that was statistically similar to the corresponding results of CET. It appears that no differences occurred for the lipid profile, serum levels of inflammatory markers, myocardial cell injury markers and skeletal muscle damage markers after any training period. The SIT protocol can be recommended as a time-efficient strategy after a moderate-intensity training period.

The major limitation of the current study is the relatively small sample size and the absence of control of the caloric intake of the subjects. Therefore, the results of this study should be considered in terms of the assumption that each subject followed his regular daily diet regimen according to the instructions of the researcher. Further studies that will be conducted on large samples with strict control of caloric intake will provide more reliable information about the SIT modality for the relevant areas of study.

\section{Acknowledgements}

The author would like to thank Asst. Prof. Dr. Ozgur Ozkaya for assistance in the preparation of this manuscript, Dr. Ekim Pekunlu for assistance in statistical evaluation, and Dr. Gorkem Balci and Dr. Faik Vural for their technical assistance in data collection.

\section{References}

Bayati M, Farzad B, Gharakhaniou R, Agha-Alinejad H. A practical model of low-volume high-intensity 
interval training induces performance and metabolic adaptations that resemble 'all-out' sprint interval training. J Sports Sci Med, 2011; 10: 571-576

Boer PH, Meeus M, Terblanche H, Rombaut L, Wandele ID, Hermans L, Gysel T, Ruige J, Calders P. The influence of sprint interval training on body composition, physical and metabolic fitness in adolescents and young adults with intellectual disability: a randomized controlled trial. Clin Rehabil, 2013; August 20, doi: 10.1177/0269215513498609

Boutcher SH. High-Intensity Intermittent Exercise and Fat Loss. J Obesity, 2011; Article ID 868305, 10 pages doi:10.1155/2011/868305

Burgomaster KA, Heigenhauser GJ, Gibala MJ. Effect of short-term sprint interval training on human skeletal muscle carbohydrate metabolism during exercise and time-trial performance. J Appl Physiol (1985), 2006; 100(6): 2041-2047

Burgomaster KA, Howarth KR, Phillips SM, Rakobowchuk M, Macdonald MJ, McGee SL, Gibala MJ. Similar metabolic adaptations during exercise after low volume sprint interval and traditional endurance training in humans. J Physiol, 2008; 586(1): 151-160

Burgomaster KA, Hughes SC, Heigenhauser GJF, Bradwell SN, Gibala MJ. Six sessions of sprint interval training increases muscle oxidative potential and cycle endurance capacity in humans. J Appl Physiol, 2005; 98: 1985-1990

Clarkson PM, Hubal MJ. Exercise-induced muscle damage in humans. Am J Phys Med Rehabil, 2002; 81(11 Suppl): S52-69

Crouse SF, O'Brien BC, Grandjean PW, Lowe RC, Rohack JJ, Green JS, Tolson H. Training intensity, blood lipids, and apolipoproteins in men with high cholesterol. J Appl Physiol, 1997; 82: 270-277

Daussin FN, Zoll J, Dufour SP, Ponsot E, Lonsdorfer-Wolf E, Doutreleau S, Mettauer B, Piquard F, Geny B, Richard R. Effect of interval versus continuous training on cardiorespiratory and mitochondrial functions: relationship to aerobic performance improvements in sedentary subjects. Am J Physiol Regul Integr Comp Physiol, 2008; 295: R264-R272

Davies E, Gawad Y, Takahashi M, Shi Q, Lam P, Styba G, Lau A, Heeschen C, Usategui M, Jackowski G. Analytical performance and clinical utility of a sensitive immunoassay for determination of human cardiac troponin I. Clin Biochem, 1997; 30: 479-490

Donnelly JE, Blair SN, Jakicic JM, Manore MM, Rankin JW, Smith BK. American College of Sports Medicine Position Stand. Appropriate physical activity intervention strategies for weight loss and prevention of weight regain for adults. Med Sci Sports Exerc, 2009; 41: 459-471

Gibala MJ, Little JP, Essen MV, Wilkin GP, Burgomaster KA, Safdar A, Raha S, Tarnopolsky MA. Short-term sprint interval versus traditional endurance training: similar initial adaptations in human skeletal muscle and exercise performance. J Physiol, 2006; 575(3): 901-911

Gist NH, Fedewa MV, Dishman RK, Cureton KJ. Sprint Interval Training Effects on Aerobic Capacity: A Systematic Review and Meta-Analysis. Sports Med, 2014; 44(2): 269-279

Hazell TJ, Hamilton CD, Olver TD, Lemon PW. Running sprint interval training induces fat loss in women. Appl Physiol Nutr Metab, 2014; 18: 1-7

Hazell TJ, Olver TD, Hamilton CD, Lemon P WR. Two minutes of sprint-interval exercise elicits 24-hr oxygen consumption similar to that of $30 \mathrm{~min}$ of continuous endurance exercise. Int J Sport Nutr Exerc Metab, 2012; 22(4): 276-283

Hovanloo F, Arefirad T, Ahmadizad S. Effects of sprint interval and continuous endurance training on serum levels of inflammatory biomarkers. J Diabetes Metab Disord, 2013; 12(1): 22

Jaffe AS, Garfinkel BT, Ritter CS, Sobel BE. Plasma mb creatine kinase after vigorous exercise in professional 
athletes. Am J Cardiol, 1984; 53(6): 856-858

King J, Broeder C, Browder K, Panton L. A comparison of interval vs steady-state exercise on substrate utilization in overweight women. Med Sci Sports Exerc, 2002; 33: 228

Lohman TG, Roche AF, Martorell R. Anthropometric Standardization Reference Manual Champaign. IL: Human Kinetics, 1-71; 1988

MacDougall JD, Hicks AL, MacDonald JR, McKelvie RS, Green HJ, Smith KM. Muscle performance and enzymatic adaptations to sprint interval training. J Appl Physiol, 1998; 84(6): 2138-2142

Macpherson RE, Hazell TJ, Olver TD, Paterson DH, Lemon PW. Run sprint interval training improves aerobic performance but not maximal cardiac output. Med Sci Sports Exerc, 2011; 43(1): 115-122

Markovitch D, Tyrrell R, Thompson D. Acute moderate-intensity exercise in middle-aged men has neither an anti-nor proinflammatory effect. J Appl Physiol, 2008; 105(1): 260-265

Martínez S, Pasquarelli Bruno N, Romaguera D, Arasa C, Tauler P, Aguiló A. Anthropometric characteristics and nutritional profile of young amateur swimmers. J Strength Cond Res, 2011; 25(4): 1126-1133

Moseley L, Jeukendrup AE. The reliability of cycling efficiency. Med Sci Sports Exerc, 2001; 33(4): 621-627

Nishi Y. Measurement of thermal balance of man. In: Cena K, Clark JA, (Eds.) Bioengineering Thermal Physiology and Comfort. New York: Elsevier, 29-39; 1981

O'Donovan G, Owen A, Bird SR, Kearney EM, Nevill AM, Jones DW, Woolf-May K. Changes in cardiorespiratory fitness and coronary heart disease risk factors following 24 wk of moderate- or highintensity exercise of equal energy cost. J Appl Physiol, 2005; 98: 1619-1625

Ozkaya O, Colakoglu M, Kuzucu EO, Delextrat A. An elliptical trainer may render the Wingate all-out test more anaerobic. J Strength Cond Res, 2014; 28(3): 643-650

Parolin ML, Chesley A, Matsos MP, Spriet LL, Jones NL, Heigenhauser GJF. Regulation of skeletal muscle glycogen phosphorylase and PDH during maximal intermittent exercise. Am J Physiol, 1999; 277: E890-E900

Perry CGR, Heigenhauser GJF, Bonen A, Spriet LL. High intensity aerobic interval training increases fat and carbohydrate metabolic capacities in human skeletal muscle. Appl Physiol Nutr Metab, 2008; 33: 11121123

Priest JB, Oei TO, Moorehead WR. Exercise-induced changes in common laboratory tests. Am J Clin Pathol, 1982; 77: 285-289

Robson-Ansley PJ, Blannin A, Gleeson M. Elevated plasma interleukin-6 levels in trained male triathletes following an acute period of intense interval training. Eur J Appl Physiol, 2007; 99: 353-360

Rogers MA, Stull GA, Apple FS. Creatine kinase isoenzyme activities in men and women following a marathon race. Med Sci Sports Exerc, 1985; 17: 679-682

Sandvei M, Jeppesen PB, Støen L, Litleskare S, Johansen E, Stensrud T, Enoksen E, Hautala A, Martinmäki K, Kinnunen $\mathrm{H}$, Tulppo M, Jensen J. Sprint interval running increases insulin sensitivity in young healthy subjects. Arch Physiol Biochem, 2012; 118(3): 139-147

Shave R, Baggish A, George K, Wood M, Scharhag J, Whyte G, Gaze D, Thompson PD. Exercise-Induced Cardiac Troponin Elevation. Evidence, Mechanisms, and Implications. Am Coll Cardiol, 2010; 56(3): $169-176$

Siahkouhian M, Khodadadi D, Shahmoradi K. Effects of high intensity interval training on aerobic and anaerobic indices: Comparison of physically active and inactive men. Sci Sports, 2013; 28(5): e119-e125

Sloth M, Sloth D, Overgaard K, Dalgas U. Effects of sprint interval training on maxVO $\mathrm{V}_{2}$ and aerobic exercise performance: A systematic review and meta-analysis. Scand J Sci Sports, 2013; 23(6): e341-e352 
Smith JE, Garbutt G, Lopes P, Tunstall Pedoe D. Effects of prolonged strenuous exercise (marathon running) on biochemical and haematological markers used in the investigation of patients in the emergency department. Br J Sports Med, 2004; 38: 292-294

Stepto NK, Martin DT, Fallon KE, Hawley JA. Metabolic demands of intense aerobic interval training in competitive cyclists. Med Sci Sports Exerc, 2001; 33(2): 303-310

Toft AD, Jensen LB, Bruunsgaard H, Ibfelt T, Halkjaer-Kristensen J, Febbraio M, Pedersen BK. Cytokine response to eccentric exercise in young and elderly humans. Am J Physiol Cell Physiol, 2002; 283(1): C289-295

Tremblay A, Simoneau JA, Bouchard C. Impact of exercise intensity on body fatness and skeletal muscle metabolism. Metabolism, 1994; 43(7): 814-818

Trilk JL, Singhal A, Bigelman KA, Cureton KJ. Effect of sprint interval training on circulatory function during exercise in sedentary, overweight/obese women. Eur J Appl Physiol, 2011; 111(8): 1591-1597

Vidotto C, Tschan H, Atamaniuk J, Pokan R, Bachl N, Müller MM. Responses of N- Terminal Pro-Brain Natriuretic Peptide (NT-proBNP) and Cardiac Troponin I (cTnI) to Competitive Endurance Exercise in Recreational Athletes. Int J Sports Med, 2005; 26: 645-650

Whyte LJ, Gill JMR, Cathcart AJ. Effect of 2 weeks of sprint interval training on health-related outcomes in sedentary overweight/obese men. Metab-Clin Exp, 2010; 59(10): 1421-1428

\section{Corresponding author:}

\section{Gulbin Rudarli Nalcakan}

Ege University School of Physical Education and Sports, Bornova - Izmir - Turkiye.

Phone number: 009023234257 14, fax: 00902323399000

E-mail: gulbinrn@gmail.com 